\title{
The Uses of 2-Amino-4-Phenylthiazole in the Synthesis of Coumarin, Pyran, Pyridine and Thiazole Derivatives with Antitumor Activities
}

\author{
Faten I. Hamed', Abeer A. Mohamed'2, Amr S. Abouzied ${ }^{1,3}$ \\ ${ }^{1}$ National Organization for Drug Control \& Research, Cairo, Egypt \\ ${ }^{2}$ National Organization for Research and control of Biologicals, Giza, Egypt \\ ${ }^{3}$ Department of Pharmaceutical Chemistry, College of Pharmacy, University of Hail, Hail, Kingdom of Saudi Arabia \\ Email: fatenismail@yahoo.com
}

How to cite this paper: Hamed, F.I., Mohamed, A.A. and Abouzied, A.S. (2017) The Uses of 2-Amino-4-Phenylthiazole in the Synthesis of Coumarin, Pyran, Pyridine and Thiazole Derivatives with Antitumor Activities. Open Access Library Journal, 4: e3526.

https://doi.org/10.4236/oalib.1103526

Received: March 15, 2017

Accepted: May 1, 2017

Published: May 4, 2017

Copyright $\odot 2017$ by authors and Open Access Library Inc.

This work is licensed under the Creative Commons Attribution International License (CC BY 4.0).

http://creativecommons.org/licenses/by/4.0/

\begin{abstract}
The thiazole derivative $\mathbf{3}$ was used for a series of heterocyclization reaction to produce pyran, pyridine and thiazole derivatives. The cytotoxicity of the newly synthesized compounds was studied against the six cancer cell lines namely NUGC, HR, DLD1, HA22T, HEPG2, MCF, HONE1 and normal fibroblast cells (WI38). The results showed that most of the synthesized compounds were of high potency. Among the tested compounds, 2-Amino-4-(4-chlorophenyl)-6-(4-phenylthiazol-2-yl)-4H-pyran-3,5-dicarbonitrile 17b showed the highest potency among the tested compounds.
\end{abstract}

\section{Subject Areas \\ Organic Chemistry}

Keywords

Thiazole, Pyran, Pyridine, Antitumor

\section{Introduction}

Thiazole is a core structural motif present in a variety of natural products, such as vitamin B1 (thiamine) and penicillin. Thiazole derivatives also exhibit a broad spectrum of medicinal and biological properties, such as antibacterial, antifungal [1], anti-inflammatory [2], antiviral [3], antimalarial [4] and anti-HIV activities [5]. Thiazole analogs have also been reported as ligands at estrogen receptors [6], neuropeptide Y5 [7], adenosine receptors [8], and act as inhibitors of human platelet aggregation factor [9], urokinase [10] and poly (ADP-Ribose) polymerase-1 [11]. Selenazoles have been reported to possess antibacterial [12], and su- 
peroxide anion scavenging activity [13], and exhibit cytotoxicity and DNA fragmentation effects in human HT-1080 fibrosarcoma cells [14]. The structures of sulfathiazole, meloxicam, and selenazofurin and their pharmacological activities are given in Figure 1.

\section{Results and Discussion}

The reaction of $₫$-bromoacetophenone (1) with thiourea (2) in ethanol gave the thiazole derivative (3) [15].

The latter compound underwent acetylation when reacted with acetic anhydride to give the $\mathrm{N}$-acetyl derivative $\mathbf{5}$. The structure of compound $\mathbf{5}$ was confirmed on the basis of analytical and spectral data. The reaction of compound 3 with phenylisothiocyanate gave the N-phenylthiourea derivative 7. On the other hand, the reaction of compound 3 with ethyl cyanoacetate in dimethylformamide gave $\mathrm{N}$-cyanoacetamide derivative $\mathbf{9}$. The reaction of compound $\mathbf{9}$ with any of the aromatic aldehydes namely benzaldehyde (10a), 4-chlorobenzaldehyde (10b) or 4-methoxybenzaldehyde (10c) gave benzylidene derivatives 11a-c, respectively. In addition, the reaction of compound 9 with salicylaldehyde (12) gave the coumarin derivative 13 (Figure 2).

The structure of compound 13 was established on the basis of analytical and spectral data. Thus, the ${ }^{1} \mathrm{H}$ NMR spectrum showed $\delta=6.13$ (s, $1 \mathrm{H}$, thiazole $\left.\mathrm{H}-5\right)$, $6.29(\mathrm{~s}, 1 \mathrm{H}$, coumarin $\mathrm{H}-4), 7.21-7.43\left(\mathrm{~m}, 9 \mathrm{H}, \mathrm{C}_{6} \mathrm{H}_{5}, \mathrm{C}_{6} \mathrm{H}_{4}\right), 8.30\left(\mathrm{~s}, 1 \mathrm{H}, \mathrm{D}_{2} \mathrm{O}\right.$ exchangeable, $\mathrm{NH}$ ). The reaction of compound 9 with any of the benzenediazonium chloride derivatives $14 \mathrm{a}-\mathrm{c}$ gave aryl hydrazone derivatives $15 \mathrm{a}-\mathrm{c}$, respectively. Moreover, the multi-component reaction of compound 9 with any of the aromatic aldehydes $10 \mathrm{a}, 10 \mathrm{~b}$ or $10 \mathrm{c}$ and malononitrile (16) gave the pyran derivatives $17 \mathrm{a}-\mathrm{c}$, respectively (Figure 3 ).

The analytical and spectral data of $17 \mathrm{a}-\mathrm{c}$ were the basis of their structural identification. Thus, the ${ }^{1} \mathrm{H}$ NMR spectrum of compound $17 \mathrm{a}$ (as an example) showed $\delta=4.82\left(\mathrm{~s}, 2 \mathrm{H}, \mathrm{D}_{2} \mathrm{O}\right.$ exchangeable, $\left.\mathrm{NH}_{2}\right), 6.14$ (s, $1 \mathrm{H}$, thiazole $\left.\mathrm{H}-5\right), 6.28$ $\left(\mathrm{s}, 1 \mathrm{H}, \mathrm{D}_{2} \mathrm{O}\right.$ exchangeable, $\left.\mathrm{NH}\right), 6.49(\mathrm{~s}, 1 \mathrm{H}$, pyran $\mathrm{H}-4), 7.28-7.42(\mathrm{~m}, 10 \mathrm{H}$, $2 \mathrm{C}_{6} \mathrm{H}_{5}$ ). Similarly, the multi-component reaction of compound 9 with any of the aromatic aldehydes $10 \mathrm{a}, 10 \mathrm{~b}$ or $10 \mathrm{c}$ and ethyl cyanoacetate (8) gave the pyran derivatives $18 \mathrm{a}-\mathrm{c}$, respectively (Figure 4).

The analytical and spectral data of $18 \mathrm{a}-\mathrm{c}$ were the basis of their structural identification. In addition, the multi-component reaction of compound 9 with any of the aromatic aldehydes $10 \mathrm{a}, 10 \mathrm{~b}$ or $10 \mathrm{c}$ and thiourea (2) gave the pyrimidine derivatives $19 \mathrm{a}-\mathrm{c}$, respectively. The analytical and spectral data of $19 \mathrm{a}-\mathrm{c}$
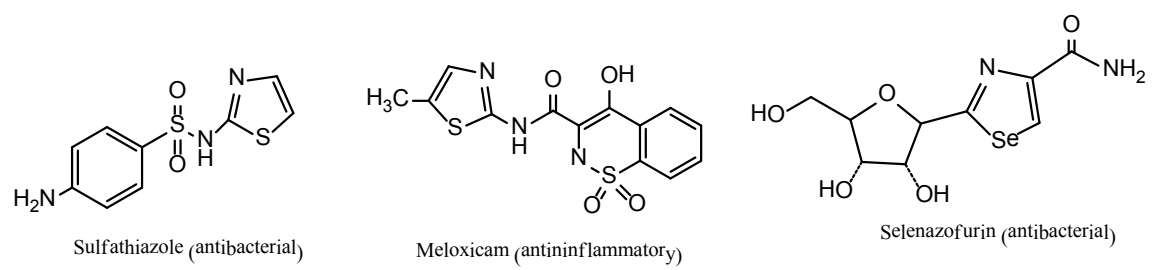

Figure 1. Biologically active thiazole and selenazole derivatives. 


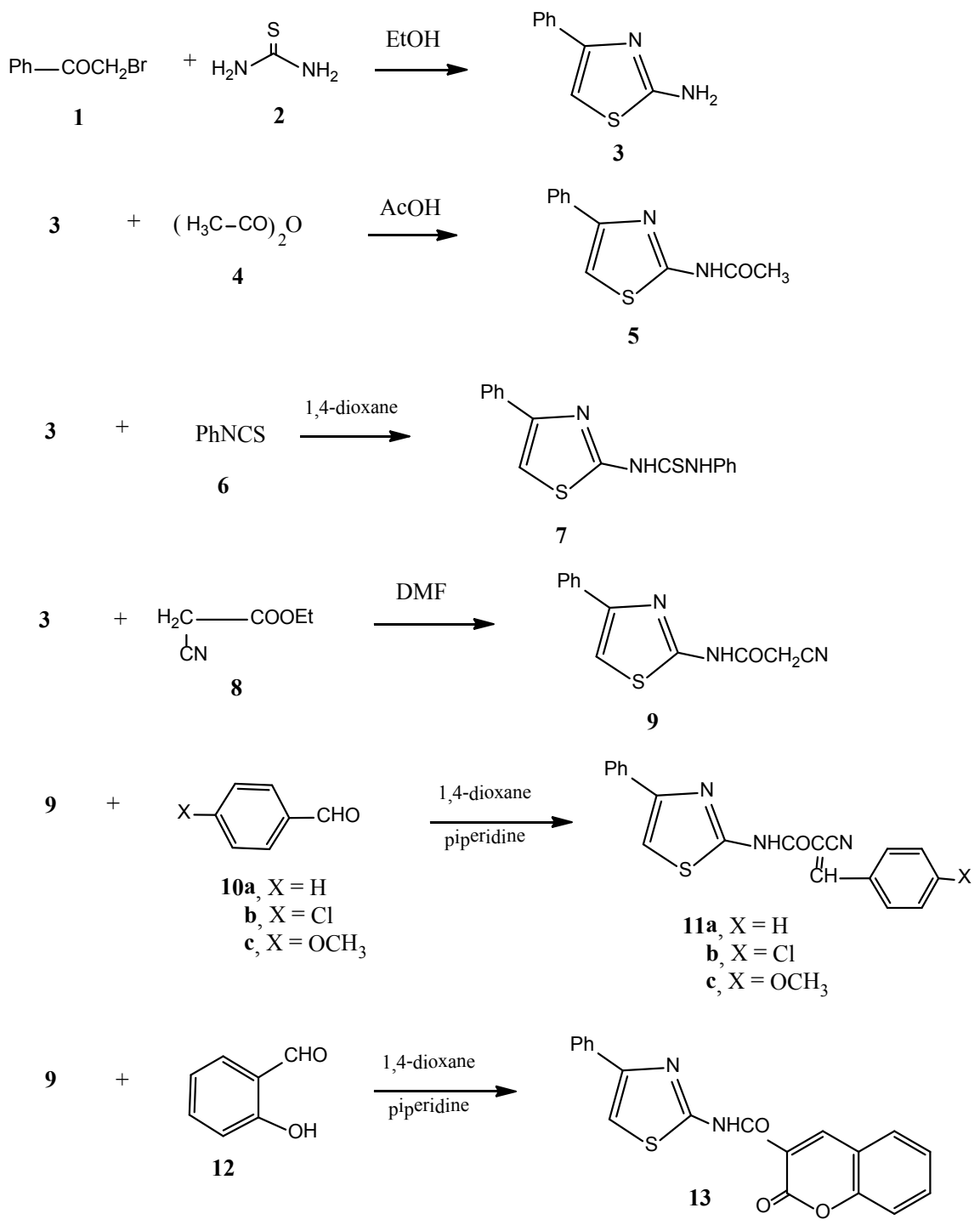

Figure 2. Compounds 3, 5, 7, 9,11a-c, 13.

were the basis of their structural identification. Thus, the ${ }^{1} \mathrm{H}$ NMR spectra of compound 19a (as an example) showed $\delta=6.18$ (s, 1H, thiazole H-5), 6.28 (s, $1 \mathrm{H}, \mathrm{D}_{2} \mathrm{O}$ exchangeable, $\left.\mathrm{NH}\right), 7.29-7.36\left(\mathrm{~m}, 10 \mathrm{H}, 2 \mathrm{C}_{6} \mathrm{H}_{5}\right), 8.24\left(\mathrm{~s}, 1 \mathrm{H}, \mathrm{D}_{2} \mathrm{O}\right.$ exchangeable, NH). Compound 9 was capable for thiazole synthesis, thus the reaction of compound 9 with elemental sulfur and phenylisothiocyanate (6) gave the thiazole derivative 20 .

\section{Experiment}

\section{General}

All melting points were determined on an electrothermal digital melting point apparatus and are uncorrected. IR spectra ( $\mathrm{KBr}$ discs) were recorded on a FTIR plus 460 or PyeUnicam SP-1000 spectrophotometer. ${ }^{1} \mathrm{H}$ NMR spectra were recorded with Varian Gemini-200 (200 MHz) and Jeol AS $500 \mathrm{MHz}$ instruments spectra were performed in DMSO- $d 6$ as solvent using TMS as internal standard- 


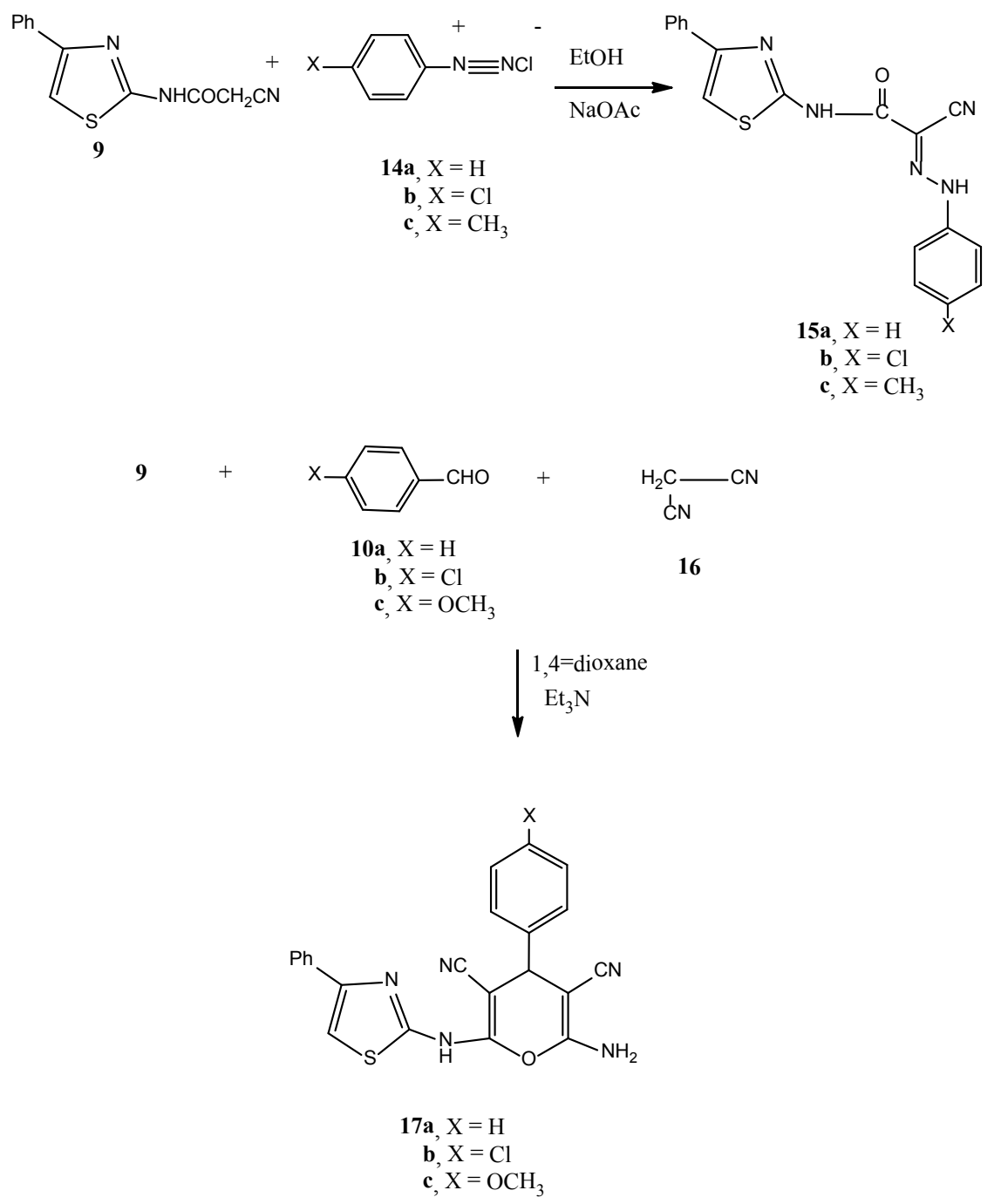

Figure 3. Compounds 15a-c, 17a-c.

and chemical shifts are expressed as $\delta$ ppm. MS (EI) spectra were recorded with Hewlett Packard 5988 A GC/MS system and GCMS-QP 1000 Ex Shimadzu instruments. Analytical data were obtained from the Micro-analytical Data Unit at Cairo University and were performed on Vario EL III Elemental analyzer. Compound 3 was synthesized according to method reported in literature [15]. All synthesized compounds are filtered using Whatman filter paper 42 Ashless.

1) $\mathrm{N}$-(4-phenylthiazol-2-yI) acetamide (5)

To a solution of compound $3(1.76 \mathrm{~g}, 0.01 \mathrm{~mol})$ in acetic acid $(40 \mathrm{~mL})$ acetic anhydride $(10 \mathrm{~mL})$ was added. The reaction mixture was heated under reflux $\left(118^{\circ} \mathrm{C}\right)$ for $2 \mathrm{~h}$ then poured onto ice/water and left to room temperature for $4 \mathrm{~h}$. The formed solid product was collected by filtration.

Yellow crystals from ethanol, yield $70 \%\left(1.52\right.$ g), m.p. $206^{\circ} \mathrm{C}-208^{\circ} \mathrm{C}$. Anal. Calculated for $\mathrm{C}_{11} \mathrm{H}_{10} \mathrm{~N}_{2} \mathrm{OS}$ (218.27): C, 60.53; H, 4.62; N, 12.83; S, 14.69. Found: C, 60.74; H, 4.59; N, 12.93; S, 14.80. MS: m/e $218\left(\mathrm{M}^{+}, 28 \%\right)$. IR, v: 3492 - 3330 (NH), $3056\left(\mathrm{CH}\right.$, aromatic), $2970\left(\mathrm{CH}_{3}\right), 1688(\mathrm{CO}), 1638(\mathrm{C}=\mathrm{C}) .{ }^{1} \mathrm{H}$ NMR (DMSO-d $\left.\mathrm{d}_{6}, 200 \mathrm{MHz}\right): \delta=2.80\left(\mathrm{~s}, 3 \mathrm{H}, \mathrm{CH}_{3}\right), 6.12(\mathrm{~s}, 1 \mathrm{H}$, thiazole $\mathrm{H}-5), 7.26$ - 


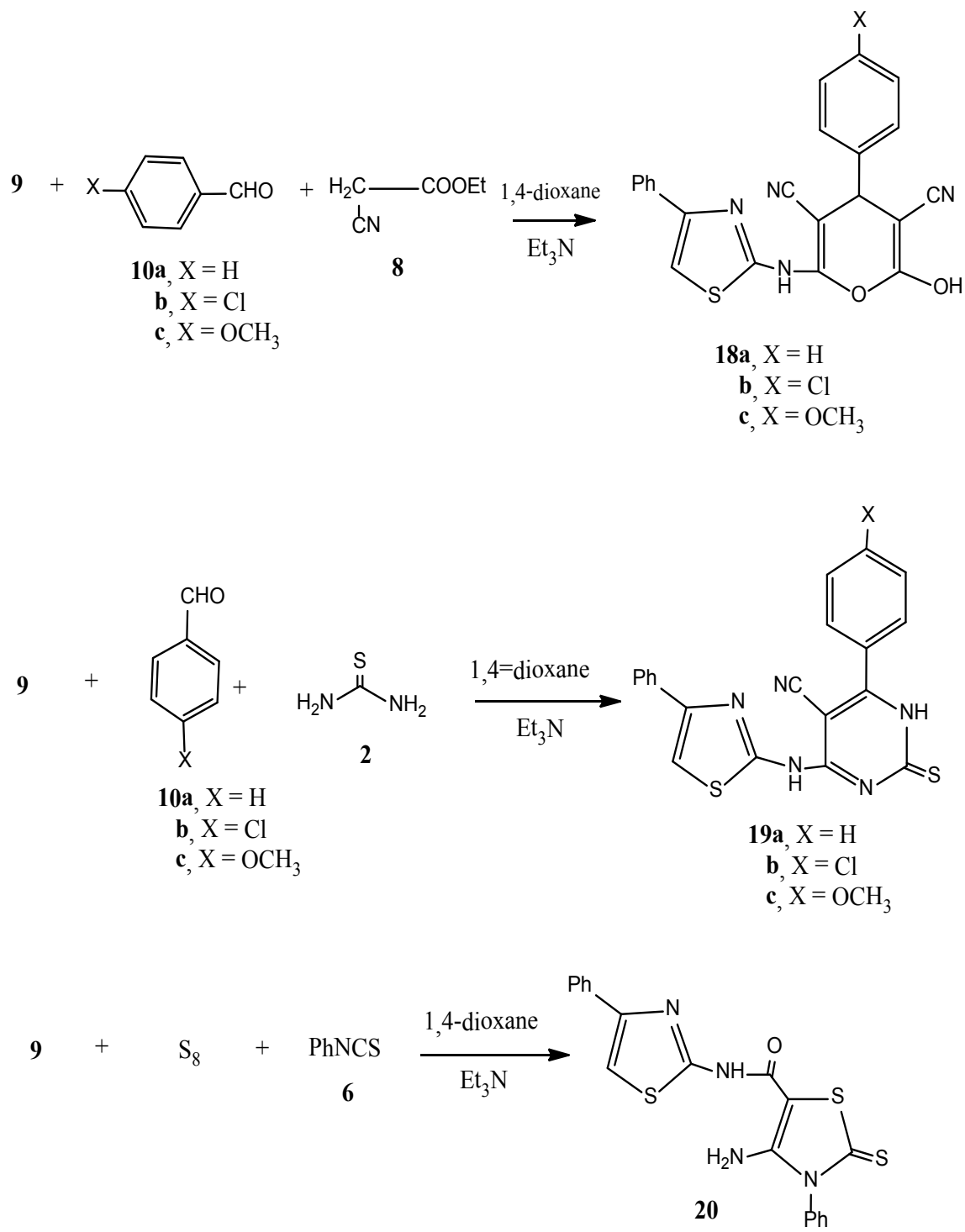

Figure 4. Compounds 18a-c, 19a-c, 20.

$7.39\left(\mathrm{~m}, 5 \mathrm{H}, \mathrm{C}_{6} \mathrm{H}_{5}\right), 8.30$ (s, $1 \mathrm{H}, \mathrm{D}_{2} \mathrm{O}$ exchangeable, $\left.\mathrm{NH}\right)$.

2) 1-phenyl-3-(4-phenylthiazol-2-yl) thiourea (7)

To a solution of compound $3(1.76 \mathrm{~g}, 0.01 \mathrm{~mol})$ in 1,4-dioxane $(20 \mathrm{~mL})$ phenylisothiocyanate $(1.35 \mathrm{~g}, 0.01 \mathrm{~mol})$ was added. The reaction mixture was heated under reflux $\left(101^{\circ} \mathrm{C}\right)$ for $3 \mathrm{~h}$ then poured onto ice/water and the formed solid product was collected by filtration.

Orange crystals from ethanol, yield $78 \%\left(2.42\right.$ g), m.p. $130^{\circ} \mathrm{C}-132^{\circ} \mathrm{C}$. Anal. Calculated for $\mathrm{C}_{16} \mathrm{H}_{13} \mathrm{~N}_{2} \mathrm{~S}_{2}$ (311.42): C, 61.71; H, 4.21; N, 13.49; S, 20.59. Found: C, 61.95; H, 4.31; N, 14.22; S, 20.72. MS: m/e 311 (M+22\%). IR, v: 3468 - 3324 $(2 \mathrm{NH}), 3054\left(\mathrm{CH}\right.$, aromatic), $1638(\mathrm{C}=\mathrm{C}) .{ }^{1} \mathrm{H}$ NMR (DMSO-d $\left.\mathrm{d}_{6}, 200 \mathrm{MHz}\right): \delta=$ $6.14(\mathrm{~s}, 1 \mathrm{H}$, thiazole $\mathrm{H}-5), 7.23-7.42\left(\mathrm{~m}, 10 \mathrm{H}, 2 \mathrm{C}_{6} \mathrm{H}_{5}\right), 8.26,8.32\left(2 \mathrm{~s}, 2 \mathrm{H}, \mathrm{D}_{2} \mathrm{O}\right.$ exchangeable, $2 \mathrm{NH}$ ).

3) 2-Cyano-N-(4-phenylthiazol-2 -yl)acetamide (9)

To a solution of compound $3(1.76 \mathrm{~g}, 0.01 \mathrm{~mol})$ in dimethylformamide (20 
$\mathrm{mL})$ ethyl cyanoacetate $(1.13 \mathrm{~g}, 0.01 \mathrm{~mol})$ was added. The reaction mixture was heated under reflux $\left(153^{\circ} \mathrm{C}\right)$ for $2 \mathrm{~h}$ then poured onto ice/water and the formed solid product was collected by filtration.

Orange crystals from ethanol, yield $67 \%\left(1.63\right.$ g), m.p. $154^{\circ} \mathrm{C}-157^{\circ} \mathrm{C}$. Anal. Calculated for $\mathrm{C}_{12} \mathrm{H}_{9} \mathrm{~N}_{3} \mathrm{OS}$ (243.28): C, 59.24; H, 3.73; N, 17.27; S, 13.18. Found: C, 59.36; H, 4.01; N, 16.96; S, 13.47. MS: m/e $243\left(\mathrm{M}^{+}, 36 \%\right)$ IR, v: 3452-3328 $(\mathrm{NH}), 3057\left(\mathrm{CH}\right.$, aromatic), $2220(\mathrm{CN}), 1678(\mathrm{CO}), 1632(\mathrm{C}=\mathrm{C}), .{ }^{1} \mathrm{H}$ NMR $\left(\mathrm{DMSO}_{6}, 200 \mathrm{MHz}\right): \delta=3.84\left(\mathrm{~s}, 2 \mathrm{H}, \mathrm{CH}_{2}\right), 6.13$ (s, 1H, thiazole H-5), 7.28 $7.39\left(\mathrm{~m}, 5 \mathrm{H}, \mathrm{C}_{6} \mathrm{H}_{5}\right), 8.30\left(\mathrm{~s}, 1 \mathrm{H}, \mathrm{D}_{2} \mathrm{O}\right.$ exchangeable, $\left.\mathrm{NH}\right)$.

4) General procedure for the synthesis of the benzylidine derivatives $11 \mathrm{a}-\mathrm{c}$

To a solution of compound $9(2.43 \mathrm{~g}, 0.01 \mathrm{~mol})$ in 1,4-dioxane $(40 \mathrm{~mL})$ containing piperidine $(0.50 \mathrm{~mL})$, any of benzaldehyde $(1.08 \mathrm{~g}, 0.01 \mathrm{~mol}), 4$-chlorobenzaldehyde $(1.40 \mathrm{~g}, 0.01 \mathrm{~mol})$ or 4-methoxybenzaldehyde $(1.36 \mathrm{~g}, 0.01 \mathrm{~mol})$ was added. The reaction mixture was heated under reflux $\left(101^{\circ} \mathrm{C}\right)$ for $3 \mathrm{~h}$ then poured onto ice/water containing few drops of hydrochloric acid. The formed solid product, formed in each case was collected by filtration.

5) 2-Cyano-3-phenyl- $N$-(4-phenylthiazol-2-yl) acrylamide (11a)

Pale brown crystals from ethanol, yield $70 \%(2.32 \mathrm{~g})$, m.p. $139^{\circ} \mathrm{C}-141^{\circ} \mathrm{C}$. Anal. Calculated for $\mathrm{C}_{19} \mathrm{H}_{13} \mathrm{~N}_{3} \mathrm{OS}$ (331.39): C, 68.86; H, 3.95; N, 12.68; S, 9.68. Found: C, 68.47; H, 4.16; N, 12.51; S, 9.38. MS: m/e $331\left(\mathrm{M}^{+}, 28 \%\right)$. IR, v: 3462 $3341(\mathrm{NH}), 3053\left(\mathrm{CH}\right.$, aromatic), $2220(\mathrm{CN}), 1682(\mathrm{CO}), 1635(\mathrm{C}=\mathrm{C}) .{ }^{1} \mathrm{H}$ NMR $\left(\mathrm{DMSO}_{-} \mathrm{d}_{6}, 200 \mathrm{MHz}\right): \delta=6.09(\mathrm{~s}, 1 \mathrm{H}, \mathrm{CH}), 6.14$ (s, 1H, thiazole H-5), 7.25-7.37 $\left(\mathrm{m}, 10 \mathrm{H}, 2 \mathrm{C}_{6} \mathrm{H}_{5}\right), 8.32\left(\mathrm{~s}, 1 \mathrm{H}, \mathrm{D}_{2} \mathrm{O}\right.$ exchangeable, $\left.\mathrm{NH}\right)$.

6) 3 -(4-chlorophenyl)-2-cyano- $N$-(4-phenylthiazol-2 -yl)acrylamide (11b)

Pale brown crystals from ethanol, yield $66 \%(2.41 \mathrm{~g})$, m.p. $188^{\circ} \mathrm{C}-191^{\circ} \mathrm{C}$. Anal. Calculated for $\mathrm{C}_{19} \mathrm{H}_{12} \mathrm{ClN}_{3} \mathrm{OS}$ (365.84): C, 62.38; H, 3.31; N, 11.49; S, 8.76. Found: C, 62.19; H, 3.53; N, 11.60; S, 8.57. MS: m/e $365\left(\mathrm{M}^{+}, 40 \%\right)$. IR, v: 3472 $3329(\mathrm{NH}), 3056\left(\mathrm{CH}\right.$, aromatic), $2222(\mathrm{CN}), 1680(\mathrm{CO}), 1632(\mathrm{C}=\mathrm{C}) .{ }^{1} \mathrm{H}$ NMR (DMSO-d $\left.{ }_{6}, 200 \mathrm{MHz}\right): \delta=6.06(\mathrm{~s}, 1 \mathrm{H}, \mathrm{CH}), 6.12$ (s, 1H, thiazole H-5), 7.23-7.42 $\left(\mathrm{m}, 9 \mathrm{H}, \mathrm{C}_{6} \mathrm{H}_{5}, \mathrm{C}_{6} \mathrm{H}_{4}\right), 8.34$ (s, $1 \mathrm{H}, \mathrm{D}_{2} \mathrm{O}$ exchangeable, $\mathrm{NH}$ ).

7) 2-cyano-3-(4-methoxyphenyl) - $N$-(4-phenylthiazol-2-yI) acrylamide (11c)

Yellow crystals from ethanol, yield 78\% (2.83 g), m.p. 166-169 ${ }^{\circ}$ C. Anal. Calculated for $\mathrm{C}_{20} \mathrm{H}_{15} \mathrm{~N}_{3} \mathrm{O}_{2} \mathrm{~S}$ (361.42): C, 66.46; H, 4.18; N, 11.63; S, 8.87. Found: C, 66.37; H, 3.86; N, 11.41; S, 8.72. MS: m/e $361\left(\mathrm{M}^{+}, 22 \%\right)$. IR, v: 3463 - 3342 $(\mathrm{NH}), 3053\left(\mathrm{CH}\right.$, aromatic), $2220(\mathrm{CN}), 1682(\mathrm{CO}), 1631(\mathrm{C}=\mathrm{C}) .{ }^{1} \mathrm{H}$ NMR $\left(\mathrm{DMSO}_{6}, 200 \mathrm{MHz}\right): \delta=3.68\left(\mathrm{~s}, 3 \mathrm{H}, \mathrm{OCH}_{3}\right), 6.08(\mathrm{~s}, 1 \mathrm{H}, \mathrm{CH}), 6.14(\mathrm{~s}, 1 \mathrm{H}$, thiazole $\mathrm{H}-5), 7.24-7.38\left(\mathrm{~m}, 9 \mathrm{H}, \mathrm{C}_{6} \mathrm{H}_{5}, \mathrm{C}_{6} \mathrm{H}_{4}\right), 8.32$ (s, 1H, $\mathrm{D}_{2} \mathrm{O}$ exchangeable, $\mathrm{NH})$.

8) 2-Oxo-N-(4-phenylthiazol-2-yI)-2 H-chromene-3-carboxamide (13)

To a solution of compound $9(2.43 \mathrm{~g}, 0.01 \mathrm{~mol})$ in 1,4-dioxane $(40 \mathrm{~mL})$ containing piperidine $(0.50 \mathrm{~mL})$ salicylaldehyde $(1.22 \mathrm{~g}, 0.01 \mathrm{~mol})$ was added. The reaction mixture was heated under reflux $\left(101^{\circ} \mathrm{C}\right)$ for $2 \mathrm{~h}$ then poured onto ice/water containing few drops of hydrochloric acid. The formed solid product was collected by filtration. 
Yellow crystals from ethanol, yield $62 \%\left(2.16\right.$ g), m.p. $122^{\circ} \mathrm{C}-124^{\circ} \mathrm{C}$. Anal. Calculated for $\mathrm{C}_{19} \mathrm{H}_{12} \mathrm{~N}_{2} \mathrm{O}_{3} \mathrm{~S}$ (348.38): C, 65.51; H, 3.47; N, 8.04; S, 9.20. Found: C, 65.44; H, 3.59; N, 7.94; S, 9.38. MS: m/e $348\left(\mathrm{M}^{+}, 18 \%\right)$. IR, v: 3439-3312 $(\mathrm{NH}), 3056\left(\mathrm{CH}\right.$, aromatic), 1690, $1682(2 \mathrm{CO}), 1665(\mathrm{C}=\mathrm{N}), 1628(\mathrm{C}=\mathrm{C}) .{ }^{1} \mathrm{H}$ NMR (DMSO-d $\left.\mathrm{d}_{6}, 200 \mathrm{MHz}\right): \delta=6.13$ (s, 1H, thiazole $\left.\mathrm{H}-5\right), 6.29(\mathrm{~s}, 1 \mathrm{H}$, coumarin $\mathrm{H}-4), 7.21-7.43\left(\mathrm{~m}, 9 \mathrm{H}, \mathrm{C}_{6} \mathrm{H}_{5}, \mathrm{C}_{6} \mathrm{H}_{4}\right), 8.30\left(\mathrm{~s}, 1 \mathrm{H}, \mathrm{D}_{2} \mathrm{O}\right.$ exchangeable, $\mathrm{NH})$.

9) General procedure for the synthesis of the aryl hydrazone derivatives $15 \mathrm{a}-\mathrm{c}$

To a cold solution $\left(0^{\circ} \mathrm{C}-5^{\circ} \mathrm{C}\right)$ of compound $9(2.43 \mathrm{~g}, 0.01 \mathrm{~mol})$ in ethanol $(40 \mathrm{~mL})$ containing sodium acetate $(2.50 \mathrm{~g})$ any of the diazonium salts namely benzenediazonium chloride $(\mathbf{1 4 a})(0.01 \mathrm{~mol})$ 4-chlorobenzene diazonium chloride $(14 \mathrm{~b})(0.01 \mathrm{~mol})$ or 4 -methylbenzenediazonium chloride $(14 \mathrm{c})(0.01 \mathrm{~mol})$ [prepared by the addition of sodium nitrite $(0.70 \mathrm{~g}, 0.01 \mathrm{~mol})$ to a cold solution $\left(0-5{ }^{\circ} \mathrm{C}\right)$ of any of aniline $(0.93 \mathrm{~g}, 0.01 \mathrm{~mol}), 4$-chloroaniline $(1.27 \mathrm{~g}, 0.01 \mathrm{~mol})$ or 4-methylaniline $(1.14 \mathrm{~g}, 0.01 \mathrm{~mol})$ in concentrated hydrochloric acid $(16 \mathrm{~mL})]$ was added. The whole reaction mixture, in each case, was stirred at room temperature for $2 \mathrm{~h}$ and the formed solid product was collected by filtration.

10) 2-Oxo- $N^{\infty}$-phenyl-2-((4-phenylthiazol-2-yl)amino) acetohydrazonoyl cyanide (15a)

Orange crystals from ethanol, yield $65 \%\left(2.24\right.$ g), m.p. $153^{\circ} \mathrm{C}-156^{\circ} \mathrm{C}$. Anal. Calculated for $\mathrm{C}_{18} \mathrm{H}_{13} \mathrm{~N}_{5} \mathrm{OS}$ (347.39): C, 62.23; H, 3.77; N, 20.16; S, 9.23. Found: C, 62.41; H, 3.54; N, 20.08; S, 9.52. MS: m/e $347\left(\mathrm{M}^{+}, 36 \%\right)$. IR, v: 3452-3316 $(2 \mathrm{NH}), 3053(\mathrm{CH}$, aromatic), $2220(\mathrm{CN}), 1686(\mathrm{CO}), 1660(\mathrm{C}=\mathrm{N}), 1626(\mathrm{C}=\mathrm{C})$. ${ }^{1} \mathrm{H}$ NMR (DMSO-d $\left.{ }_{6}, 200 \mathrm{MHz}\right): \delta=6.12(\mathrm{~s}, 1 \mathrm{H}$, thiazole H-5), 7.24-7.38 (m, $\left.10 \mathrm{H}, 2 \mathrm{C}_{6} \mathrm{H}_{5}\right), 8.26,8.30\left(2 \mathrm{~s}, 2 \mathrm{H}, \mathrm{D}_{2} \mathrm{O}\right.$ exchangeable, $\left.2 \mathrm{NH}\right)$.

11) $\quad N^{p}$-(4-Chlorophenyl)-2-oxo-2-((4-phenylthiazol-2-yl)amino) acetohydrazonoyl cyanide (15b)

Orange crystals from ethanol, yield $74 \%\left(2.82\right.$ g), m.p. $177^{\circ} \mathrm{C}-179^{\circ} \mathrm{C}$. Anal. Calculated for $\mathrm{C}_{18} \mathrm{H}_{12} \mathrm{ClN}_{5} \mathrm{OS}$ (381.84): C, 56.62; H, 3.17; N, 18.34; S, 8.40. Found: C, 56.82; H, 3.38; N, 18.51; S, 8.29. MS: m/e $381\left(\mathrm{M}^{+}, 28 \%\right)$. IR, v: $3458-3331$ $(2 \mathrm{NH}), 3056(\mathrm{CH}$, aromatic), $2222(\mathrm{CN}), 1688(\mathrm{CO}), 1653(\mathrm{C}=\mathrm{N}), 1628(\mathrm{C}=\mathrm{C})$. ${ }^{1} \mathrm{H}$ NMR (DMSO-d 6 , $\left.200 \mathrm{MHz}\right): \delta=6.18(\mathrm{~s}, 1 \mathrm{H}$, thiazole H-5), 7.22-7.41 (m, 9H, $\left.\mathrm{C}_{6} \mathrm{H}_{5}, \mathrm{C}_{6} \mathrm{H}_{4}\right), 8.28,8.31\left(2 \mathrm{~s}, 2 \mathrm{H}, \mathrm{D}_{2} \mathrm{O}\right.$ exchangeable, 2NH).

12) 2-Oxo-2-((4-phenylthiazol-2-yl) amino $)-N^{p}$-(p-tolyl)acetohydrazonoylcyanide (15c)

Orange crystals from ethanol, yield $72 \%\left(2.59\right.$ g), m.p. $203^{\circ} \mathrm{C}-206^{\circ} \mathrm{C}$. Anal. Calculated for $\mathrm{C}_{19} \mathrm{H}_{15} \mathrm{~N}_{5} \mathrm{OS}$ (361.42): C, 63.14; H, 4.18; N, 19.38; S, 8.87. Found: C, 62.97; H, 3.92; N, 19.26; S, 8.65. MS: m/e $361\left(\mathrm{M}^{+}, 38 \%\right) . \mathrm{IR}, \mathrm{v}: 3471$ - 3369 $(2 \mathrm{NH}), 3055(\mathrm{CH}$, aromatic), $2220(\mathrm{CN}), 1687(\mathrm{CO}), 1656(\mathrm{C}=\mathrm{N}), 1629(\mathrm{C}=\mathrm{C})$. ${ }^{1} \mathrm{H}$ NMR (DMSO-d, $\left.200 \mathrm{MHz}\right): \delta=2.69$ (s, 3H, $\left.\mathrm{CH}_{3}\right), 6.17$ (s, 1H, thiazole H-5), 7.24 - $7.45\left(\mathrm{~m}, 9 \mathrm{H}, \mathrm{C}_{6} \mathrm{H}_{5}, \mathrm{C}_{6} \mathrm{H}_{4}\right), 8.26,8.33$ (2s, 2H, $\mathrm{D}_{2} \mathrm{O}$ exchangeable, $\left.2 \mathrm{NH}\right)$.

13) General procedure for the synthesis of the pyran derivatives $17 \mathrm{a}-\mathrm{c}$

To a solution of compound $9(2.43 \mathrm{~g}, 0.01 \mathrm{~mol})$ in ethanol $(30 \mathrm{~mL})$ containing triethylamine $(0.50 \mathrm{~mL})$ malononitrile $(0.66 \mathrm{~g}, 0.01 \mathrm{~mol})$ and any of benzalde- 
hyde (1.06 g, $0.01 \mathrm{~mol})$, 4-chlorobenzaldehyde (1.40 g, $0.01 \mathrm{~mol})$ or 4-methoxybenzaldehyde (1.36 g, $0.01 \mathrm{~mol}$ ) was added. The reaction mixture, in each case, was heated under reflux $\left(78^{\circ} \mathrm{C}\right)$ for $3 \mathrm{~h}$ then left to cool and the formed solid product was collected by filtration.

14) 2-Amino-4-phenyl-6-(4-phenylthiazol-2-yl)amino)-4H-pyran-3,5-dicarbonitrile (17a)

Orange crystals from ethanol, yield $83 \%$ (3.29 g), m.p. $213^{\circ} \mathrm{C}-215^{\circ} \mathrm{C}$. Anal. Calculated for $\mathrm{C}_{22} \mathrm{H}_{15} \mathrm{~N}_{5} \mathrm{OS}$ (397.45): C, 66.48; H, 3.80; N, 17.62; S, 8.07. Found: C, 66.73; H, 3.92; N, 17.94; S, 8.19. MS: m/e 397 (M+, 26\%). IR, v: 3462 - 3338 $\left(\mathrm{NH}, \mathrm{NH}_{2}\right), 3056\left(\mathrm{CH}\right.$, aromatic), $2221(\mathrm{CN}), 1662(\mathrm{C}=\mathrm{N}), 1621(\mathrm{C}=\mathrm{C}) .{ }^{1} \mathrm{H}$ NMR (DMSO-d $\left.{ }_{6}, 200 \mathrm{MHz}\right): \delta=4.82\left(\mathrm{~s}, 2 \mathrm{H}, \mathrm{D}_{2} \mathrm{O}\right.$ exchangeable, $\left.\mathrm{NH}_{2}\right), 6.14(\mathrm{~s}, 1 \mathrm{H}$, thiazole $\mathrm{H}-5), 6.28\left(\mathrm{~s}, 1 \mathrm{H}, \mathrm{D}_{2} \mathrm{O}\right.$ exchangeable, $\left.\mathrm{NH}\right), 6.49(\mathrm{~s}, 1 \mathrm{H}$, pyran $\mathrm{H}-4)$, 7.28-7.42 (m, 10H, 2 $\left.\mathrm{C}_{6} \mathrm{H}_{5}\right)$.

15) 2-Amino-4-(4-chlorophenyl)-6-(4-phenylthiazol-2-yl)amino)-4H-pyran3,5-dicarbonitrile (17b)

Orange crystals from ethanol, yield $76 \%$ (3.27 g), m.p. $183^{\circ} \mathrm{C}-185^{\circ} \mathrm{C}$. Anal. Calculated for $\mathrm{C}_{22} \mathrm{H}_{14} \mathrm{ClN}_{5} \mathrm{OS}$ (431.90): C, 61.18; H, 3.27; N, 16.22; S, 7.42. Found: C, 61.28; H, 3.37; N, 16.49; S, 7.80. MS: m/e $431\left(\mathrm{M}^{+}, 18 \%\right)$. IR, v: 3462 - 3338 $\left(\mathrm{NH}, \mathrm{NH}_{2}\right), 3056\left(\mathrm{CH}\right.$, aromatic), $2222(\mathrm{CN}), 1659(\mathrm{C}=\mathrm{N}), 1626(\mathrm{C}=\mathrm{C}) .{ }^{1} \mathrm{H}$ NMR $\left(\mathrm{DMSO}_{6}, 200 \mathrm{MHz}\right): \delta=4.80\left(\mathrm{~s}, 2 \mathrm{H}, \mathrm{D}_{2} \mathrm{O}\right.$ exchangeable, $\left.\mathrm{NH}_{2}\right), 6.17(\mathrm{~s}, 1 \mathrm{H}$, thiazole $\mathrm{H}-5), 6.26$ (s, 1H, $\mathrm{D}_{2} \mathrm{O}$ exchangeable, $\left.\mathrm{NH}\right), 6.49(\mathrm{~s}, 1 \mathrm{H}$, pyran $\mathrm{H}-4), 7.22$ - $7.48\left(\mathrm{~m}, 9 \mathrm{H}, \mathrm{C}_{6} \mathrm{H}_{5}, \mathrm{C}_{6} \mathrm{H}_{4}\right)$

16) 2-Amino-6-(4-phenylthiazol-2-yl)amino)-4-(p-tolyl)-4H-pyran-3,5-dicarbonitrile (17c)

Orange crystals from ethanol, yield $68 \%(2.90 \mathrm{~g})$, m.p. $97^{\circ} \mathrm{C}-99^{\circ} \mathrm{C}$. Anal. Calculated for $\mathrm{C}_{23} \mathrm{H}_{17} \mathrm{~N}_{5} \mathrm{O}_{2} \mathrm{~S}$ (427.48): C, 64.62; H, 4.01; N, 16.38; S, 7.50. Found: C, 64.80; H, 4.26; N, 16.60; S, 7.44. MS: m/e $427\left(\mathrm{M}^{+}, 33 \%\right)$. IR, v: 3462 - 3338 $\left(\mathrm{NH}, \mathrm{NH}_{2}\right), 3055\left(\mathrm{CH}\right.$, aromatic), $2220(\mathrm{CN}), 1655(\mathrm{C}=\mathrm{N}), 1628(\mathrm{C}=\mathrm{C}) .{ }^{1} \mathrm{H}$ NMR (DMSO-d $\mathrm{d}_{6}, 200 \mathrm{MHz}$ ): $\delta=3.77\left(\mathrm{~s}, 3 \mathrm{H}, \mathrm{CH}_{3}\right), 4.81$ (s, $2 \mathrm{H}, \mathrm{D}_{2} \mathrm{O}$ exchangeable, $\mathrm{NH}_{2}$ ), 6.19 (s, 1H, thiazole $\left.\mathrm{H}-5\right), 6.28$ (s, 1H, D2O exchangeable, $\mathrm{NH}$ ), 6.46 (s, $1 \mathrm{H}$, pyran $\mathrm{H}-4), 7.24-7.45\left(\mathrm{~m}, 9 \mathrm{H}, \mathrm{C}_{6} \mathrm{H}_{5}, \mathrm{C}_{6} \mathrm{H}_{4}\right)$.

17) General procedure for the synthesis of the pyran derivatives $18 \mathrm{a}-\mathrm{c}$

To a solution of compound $9(2.43 \mathrm{~g}, 0.01 \mathrm{~mol})$ in ethanol $(30 \mathrm{~mL})$ containing triethylamine $(0.50 \mathrm{~mL})$ ethyl cyanoacetate $(1.13 \mathrm{~g}, 0.01 \mathrm{~mol})$ and any of benzaldehyde (1.06 g, $0.01 \mathrm{~mol})$, 4-chlorobenzaldehyde (1.40 g, $0.01 \mathrm{~mol})$ or 4-methoxybenzaldehyde $(1.36 \mathrm{~g}, 0.01 \mathrm{~mol})$ was added. The reaction mixture, in each case, was heated under reflux $\left(78^{\circ} \mathrm{C}\right)$ for $6 \mathrm{~h}$ then left to cool and the formed solid product was collected by filtration.

18) 2-Hydroxy-4-phenyl-6-(4-phenylthiazol-2-yl)amino)-4H-pyran-3,5-dicarbonitrile (18a)

Orange crystals from ethanol, yield $70 \%(2.79 \mathrm{~g})$, m.p. $228^{\circ} \mathrm{C}-230^{\circ} \mathrm{C}$. Anal. Calculated for $\mathrm{C}_{22} \mathrm{H}_{14} \mathrm{~N}_{4} \mathrm{O}_{2} \mathrm{~S}$ (398.44): C, 66.32; H, 3.54; N, 14.06; S, 8.05. Found: C, 66.88; H, 3.51; N, 14.14; S, 8.40. MS: m/e $398\left(\mathrm{M}^{+}, 19 \%\right)$. IR, v: $3560-3328$ $(\mathrm{NH}, \mathrm{OH}), 3056\left(\mathrm{CH}\right.$, aromatic), $2223(\mathrm{CN}), 1660(\mathrm{C}=\mathrm{N}), 1626(\mathrm{C}=\mathrm{C}) .{ }^{1} \mathrm{H}$ NMR 
(DMSO-d $\left.{ }_{6}, 200 \mathrm{MHz}\right): \delta=6.16(\mathrm{~s}, 1 \mathrm{H}$, thiazole $\mathrm{H}-5), 6.46$ (s, $1 \mathrm{H}$, pyran H-4), $6.49\left(\mathrm{~s}, 1 \mathrm{H}, \mathrm{D}_{2} \mathrm{O}\right.$ exchangeable, $\left.\mathrm{NH}\right), 7.29-7.36\left(\mathrm{~m}, 10 \mathrm{H}, 2 \mathrm{C}_{6} \mathrm{H}_{5}\right), 10.20(\mathrm{~s}, 1 \mathrm{H}$, $\mathrm{D}_{2} \mathrm{O}$ exchangeable, $\left.\mathrm{OH}\right)$.

19) 4-(4-Chlorophenyl)-2-hydroxy-6-(4-phenylthiazol-2-yl)amino)-4H-pyran-3,5-dicarbonitrile (18b)

Yellow crystals from ethanol, yield $80 \%$ (3.46 g), m.p. $220^{\circ} \mathrm{C}-223^{\circ} \mathrm{C}$. Anal. Calculated for $\mathrm{C}_{22} \mathrm{H}_{13} \mathrm{ClN}_{4} \mathrm{O}_{2} \mathrm{~S}$ (432.88): C, 61.04; H, 3.03; N, 12.94; S, 7.41. Found: C, 61.42; H, 3.02; N, 12.83; S, 7.83. MS: m/e $432\left(\mathrm{M}^{+}, 20 \%\right)$. IR, v: 3560 $3328(\mathrm{NH}, \mathrm{OH}), 3054\left(\mathrm{CH}\right.$, aromatic), $2220(\mathrm{CN}), 1659(\mathrm{C}=\mathrm{N}), 1624(\mathrm{C}=\mathrm{C}) .{ }^{1} \mathrm{H}$ NMR (DMSO-d $\left.{ }_{6}, 200 \mathrm{MHz}\right): \delta=6.13(\mathrm{~s}, 1 \mathrm{H}$, thiazole H-5), 6.47 (s, 1H, pyran $\mathrm{H}-4), 6.6$ (s, $1 \mathrm{H}, \mathrm{D}_{2} \mathrm{O}$ exchangeable, $\mathrm{NH}$ ), 7.23 - 7.47 (m, 9H, $\left.\mathrm{C}_{6} \mathrm{H}_{5}, \mathrm{C}_{6} \mathrm{H}_{4}\right), 10.22$ (s, $1 \mathrm{H}, \mathrm{D}_{2} \mathrm{O}$ exchangeable, $\left.\mathrm{OH}\right)$.

20) 2-Hydroxy-6-(4-phenylthiazol-2 -yl)amino)-4-(p-tolyl)-4H-pyran-3,5-dicarbonitrile (18c)

Orange crystals from ethanol, yield $72 \%\left(3.08\right.$ g), m.p. $234^{\circ} \mathrm{C}-237^{\circ} \mathrm{C}$. Anal. Calculated for $\mathrm{C}_{23} \mathrm{H}_{16} \mathrm{~N}_{4} \mathrm{O}_{3} \mathrm{~S}$ (428.46): C, 64.47; H, 3.76; N, 13.08; S, 7.48. Found: C, 64.43; H, 3.91; N; 13.22; S, 7.86. MS: m/e 428 (M+, 20\%). IR, v: 3560 - 3328 $(\mathrm{NH}, \mathrm{OH}), 3056\left(\mathrm{CH}\right.$, aromatic), $2223(\mathrm{CN}), 1652(\mathrm{C}=\mathrm{N}), 1623(\mathrm{C}=\mathrm{C}) .{ }^{1} \mathrm{H}$ NMR (DMSO-d $\left.\mathrm{d}_{6}, 200 \mathrm{MHz}\right): \delta=3.79\left(\mathrm{~s}, 3 \mathrm{H}, \mathrm{CH}_{3}\right), 6.16$ (s, 1H, thiazole H-5), 6.27 (s, $1 \mathrm{H}, \mathrm{D}_{2} \mathrm{O}$ exchangeable $\left.\mathrm{NH}\right), 6.48(\mathrm{~s}, 1 \mathrm{H}$, pyran $\mathrm{H}-4), 7.28-7.41\left(\mathrm{~m}, 9 \mathrm{H}, \mathrm{C}_{6} \mathrm{H}_{5}\right.$, $\left.\mathrm{C}_{6} \mathrm{H}_{4}\right), 10.18$ (s, 1H, $\mathrm{D}_{2} \mathrm{O}$ exchan- geable, $\left.\mathrm{OH}\right)$.

21) General procedure for the synthesis of the pyrimidine derivatives 19a-c

To a solution of compound $9(2.43 \mathrm{~g}, 0.01 \mathrm{~mol})$ in ethanol $(30 \mathrm{~mL})$ containing triethylamine $(0.50 \mathrm{~mL})$ thiourea $(0.76 \mathrm{~g}, 0.01 \mathrm{~mol})$ and any of benzaldehyde (1.06 g, $0.01 \mathrm{~mol})$, 4-chlorobenzaldehyde (1.40 g, $0.01 \mathrm{~mol})$ or 4-methoxybenzaldehyde (1.36 g, $0.01 \mathrm{~mol})$ was added. The reaction mixture, in each case, was heated under reflux $\left(78^{\circ} \mathrm{C}\right)$ for $6 \mathrm{~h}$ then left to cool and the formed solid product was collected by filtration.

22) 6-Phenyl-4-(4-phenylthiazol-2-yl)amino)-2-thioxo-1,2-dihydropyrimidine-5-carbonitrile (19a)

Orange crystals from ethanol, yield $66 \%(2.55 \mathrm{~g})$, m.p. $162^{\circ} \mathrm{C}-165^{\circ} \mathrm{C}$. Anal. Calculated for $\mathrm{C}_{20} \mathrm{H}_{13} \mathrm{~N}_{5} \mathrm{~S}_{2}$ (387.48): C, 61.99; H, 3.38; N, 18.07; S, 16.55. Found: C, 62.32; H, 3.49; N; 18.33; S, 16.19. MS: m/e 387 (M+25\%). IR, v: 3480 - 3337 $(2 \mathrm{NH}), 3054(\mathrm{CH}$, aromatic), $2220(\mathrm{CN}), 1663(\mathrm{C}=\mathrm{N}), 1629(\mathrm{C}=\mathrm{C}), 1205(\mathrm{C}=\mathrm{S})$. ${ }^{1} \mathrm{H}$ NMR (DMSO-d, $\left.200 \mathrm{MHz}\right): \delta=6.18$ (s, 1H, thiazole $\left.\mathrm{H}-5\right), 6.28\left(\mathrm{~s}, 1 \mathrm{H}, \mathrm{D}_{2} \mathrm{O}\right.$ exchangeable, $\mathrm{NH}), 7.29$ - $7.36\left(\mathrm{~m}, 10 \mathrm{H}, 2 \mathrm{C}_{6} \mathrm{H}_{5}\right), 8.24\left(\mathrm{~s}, 1 \mathrm{H}, \mathrm{D}_{2} \mathrm{O}\right.$ exchangeable, $\mathrm{NH})$.

23) 6-(4-Chlorophenyl)-4-(4-phenylthiazol-2-yl)amino)-2-thioxo-1,2-dihydropyrimidine-5-carbonitrile (19b)

Yellow crystals from ethanol, yield $75 \%$ (3.15 g), m.p. $133^{\circ} \mathrm{C}-135^{\circ} \mathrm{C}$. Anal. Calculated for $\mathrm{C}_{20} \mathrm{H}_{12} \mathrm{ClN}_{5} \mathrm{~S}_{2}$ (421.93): C, 56.93; H, 2.87; N, 16.60; S, 15.20 . Found: C, 56.73; H, 2.99; N; 16.83; S, 15.69. MS: m/e $421\left(\mathrm{M}^{+}, 28 \%\right)$. IR, v: 3487 $3346(2 \mathrm{NH}), 3056(\mathrm{CH}$, aromatic), $2223(\mathrm{CN}), 1656(\mathrm{C}=\mathrm{N}), 1628(\mathrm{C}=\mathrm{C}), 1221$ $(\mathrm{C}=\mathrm{S}) .{ }^{1} \mathrm{H}$ NMR (DMSO-d, $\left.200 \mathrm{MHz}\right): \delta=6.14$ (s, $1 \mathrm{H}$, thiazole H-5), $6.6(\mathrm{~s}, 1 \mathrm{H}$, 
$\mathrm{D}_{2} \mathrm{O}$ exchangeable, NH), $7.21-7.49\left(\mathrm{~m}, 9 \mathrm{H}, \mathrm{C}_{6} \mathrm{H}_{5}, \mathrm{C}_{6} \mathrm{H}_{4}\right), 8.25\left(\mathrm{~s}, 1 \mathrm{H}, \mathrm{D}_{2} \mathrm{O}\right.$ exchangeable, $\mathrm{NH})$.

24) 6-(4-Methoxyphenyl)-4-(4-phenylthiazol-2-yl)amino)-2-thioxo-1,2-dihydropyrimidine-5-carbonitrile (19c)

Orange crystals from ethanol, yield $68 \%\left(2.83\right.$ g), m.p. $177^{\circ} \mathrm{C}-179^{\circ} \mathrm{C}$. Anal. Calculated for $\mathrm{C}_{21} \mathrm{H}_{15} \mathrm{~N}_{5} \mathrm{OS}_{2}$ (417.51): C, 60.41; H, 3.62; N, 16.77; S, 15.36. Found: C, 60.52; H, 3.79; N; 16.55; S, 15.26. MS: m/e 417 (M+1 15\%). IR, v: 3480 - 3329 (2NH), $3054(\mathrm{CH}$, aromatic), $2221(\mathrm{CN}), 1658(\mathrm{C}=\mathrm{N}), 1622(\mathrm{C}=\mathrm{C}), 1205(\mathrm{C}=\mathrm{S})$. ${ }^{1} \mathrm{H}$ NMR (DMSO-d $\left.{ }_{6}, 200 \mathrm{MHz}\right): \delta=3.74\left(\mathrm{~s}, 3 \mathrm{H}, \mathrm{CH}_{3}\right), 6.16(\mathrm{~s}, 1 \mathrm{H}$, thiazole H-5), $6.36\left(\mathrm{~s}, 1 \mathrm{H}, \mathrm{D}_{2} \mathrm{O}\right.$ exchangeable, $\left.\mathrm{NH}\right), 7.23-7.46\left(\mathrm{~m}, 9 \mathrm{H}, \mathrm{C}_{6} \mathrm{H}_{5}, \mathrm{C}_{6} \mathrm{H}_{4}\right), 8.23(\mathrm{~s}, 1 \mathrm{H}$, $\mathrm{D}_{2} \mathrm{O}$ exchangeable, $\left.\mathrm{NH}\right)$.

25) 4-Amino-3-phenyl-N-(4-phenylthiazol-2-yl)amino)-2-thioxo-2,3-dihydrothiazole-5-carboxamide (20)

To a solution of compound $9(2.43 \mathrm{~g}, 0.01 \mathrm{~mol})$ in ethanol $(30 \mathrm{~mL})$ containing triethylamine $(0.50 \mathrm{~mL})$, elemental sulfur $(0.32 \mathrm{~g}, 0.01 \mathrm{~mol})$ and phenylisothiocyanate $(1.35 \mathrm{~g}, 0.01 \mathrm{~mol})$ were added. The reaction mixture, in each case, was heated under reflux $\left(78^{\circ} \mathrm{C}\right)$ for $6 \mathrm{~h}$ then left to cool then poured onto ice/water containing few drops of hydrochloric acid and the formed solid product was collected by filtration.

Orange crystals from ethanol, yield $50 \%\left(2.05\right.$ g), m.p. $164^{\circ} \mathrm{C}-167^{\circ} \mathrm{C}$. Anal. Calculated for $\mathrm{C}_{19} \mathrm{H}_{14} \mathrm{~N}_{4} \mathrm{OS}_{3}$ (410.54): C, 55.59; H, 3.44; N, 13.65; S, 23.43. Found: C, 55.73; H, 3.83; N; 13.83; S, 23.44. MS: m/e 410 (M+3 35\%). IR, v: 3475 - 3342 $\left(\mathrm{NH}, \mathrm{NH}_{2}\right), 3056(\mathrm{CH}$, aromatic), $1688(\mathrm{CO}), 1655(\mathrm{C}=\mathrm{N}), 1623(\mathrm{C}=\mathrm{C}), 1230$ $(\mathrm{C}=\mathrm{S}) .{ }^{1} \mathrm{H}$ NMR (DMSO-d $\left.\mathrm{d}_{6}, 200 \mathrm{MHz}\right): \delta=4.34\left(\mathrm{~s}, 2 \mathrm{H}, \mathrm{D}_{2} \mathrm{O}\right.$ exchangeable $\mathrm{NH}_{2}$ ), $6.19(\mathrm{~s}, 1 \mathrm{H}$, thiazole $\mathrm{H}-5), 7.23-7.46\left(\mathrm{~m}, 10 \mathrm{H}, 2 \mathrm{C}_{6} \mathrm{H}_{5}\right), 8.39\left(\mathrm{~s}, 1 \mathrm{H}, \mathrm{D}_{2} \mathrm{O}\right.$ exchangeable, $\mathrm{NH})$.

\section{Biological Activity}

\subsection{In Vitro Cytotoxic Assay}

\subsubsection{Chemicals}

Fetal bovine serum (FBS) and L-glutamine, were purchased from Gibco Invitrogen Co. (Scotland, UK). RPMI-1640 medium was purchased from Cambrex (New Jersey, USA). Dimethyl sulfoxide (DMSO), doxorubicin, penicillin, streptomycin and sulforhodamine B (SRB) were purchased from Sigma Chemical Co. (Saint Louis, USA).

\subsubsection{Cell cultures}

Were obtained from the European Collection of cell Cultures (ECACC, Salisbury, UK) and human gastric cancer (NUGC and HR), human colon cancer (DLD1), human liver cancer (HA22T and HEPG2), human breast cancer (MCF), nasopharyngeal carcinoma (HONE1) and normal fibroblast cells (WI38) were kindly provided by the National Cancer Institute (NCI, Cairo, Egypt). They grow as monolayer and routinely maintained in RPMI-1640 medium supplemented with 5\% heat inactivated FBS, $2 \mathrm{mM}$ glutamine and antibiotics (penicillin $100 \mathrm{U} / \mathrm{mL}$, streptomycin $100 \mathrm{gg} / \mathrm{mL}$ ), at $37^{\circ} \mathrm{C}$ in a humidified atmosphere 
containing $5 \% \mathrm{CO}_{2}$. Exponentially growing cells were obtained by plating $1.5 \times$ $10^{5}$ cells $/ \mathrm{mL}$ for the seven human cancer cell lines including cells derived from $0.75 \times 10^{4}$ cells $/ \mathrm{mL}$ followed by $24 \mathrm{~h}$ of incubation. The effect of the vehicle solvent (DMSO) on the growth of these cell lines was evaluated in all the experiments by exposing untreated control cells to the maximum concentration $(0.5 \%)$ of DMSO used in each assay.

The heterocyclic compounds, prepared in this study, were evaluated according to standard protocols for their in vitro cytotoxicity against six human cancer cell lines including cells derived from human gastric cancer (NUGC), human colon cancer (DLD1), human liver cancer (HA22T and HEPG2), human breast cancer (MCF), nasopharyngeal carcinoma (HONE1) and a normal fibroblast cells (WI38). All of $\mathrm{IC}_{50}$ values were listed in Table 1. Some heterocyclic compounds was observed with significant cytotoxicity against most of the cancer cell lines tested $\left(\mathrm{IC}_{50}=10-1000 \mathrm{nM}\right)$. Normal fibroblasts cells (WI38) were affected to a much lesser extent (IC50 > 10,000 nM). The reference compound used is the CHS-828 which is a pyridyl cyanoguanidine anti-tumor agent.

\subsection{Structure Activity Relationship}

It is clear from Table 1 that most of the tested compounds showed high cytotoxicity against the six cancer cell line. The thiazole derivative 3 showed moderate cytotoxicity against the six cancer cell lines. Acetylation of compound 3 to give the $\mathrm{N}$-acetyl derivative 3 did not give a remarkable difference in activity compared with the original thiazole 3 . Reaction of compound 3 with phenylisothiocyanate to give the $\mathrm{N}$-phenylthiourea derivative 7 showed also moderate potency. Similarly, the N-cyanoacetyl derivative 9 showed moderate potency against the six cancer cell lines. However, the reaction of compound 9 with any of the aromatic aldehydes gave the arylidene derivatives $11 \mathrm{a}-\mathrm{c}$. It is obvious that compound $11 \mathrm{~b}(\mathrm{X}=\mathrm{Cl})$ showed the highest potency among such series of compounds. On the other hand, 11c $\left(\mathrm{X}=\mathrm{OCH}_{3}\right)$ showed high potency against only NUGC cell lines and moderate potency against the other cell lines. The reaction of compound 9 with any of the diazonium salts $14 \mathrm{a}-\mathrm{c}$ gave the aryl hydrazone derivatives $15 \mathrm{a}-\mathrm{c}$. Compound $15 \mathrm{~b}$ with the electronegative $\mathrm{Cl}$ group showed the highest cytotoxicity among the three compounds. The multicomponent reactions of compound 9 with any of the aromatic aldehydes $10 \mathrm{a}-\mathrm{c}$ and malononitrile gave the pyran derivatives $17 \mathrm{a}-\mathrm{c}$. It is obvious from Table 1 that compounds $17 \mathrm{~b}$ and $17 \mathrm{c}$ showed high potency against the six cancer cell lines. However compound 17a showed high potency against NUGC, DLDI, HA22T, HEPG2and HONE1 cell lines and low potency against MCF cell lines. On the other hand, for the pyran derivatives $18 \mathrm{a}-\mathrm{c}$ it is clear from Table 1 that compound 18a $(\mathrm{X}=\mathrm{H})$ showed high potency against DLDI, HEPG2 and MCF cell lines with $\mathrm{IC}_{50}$ 's 368,224 and $310 \mathrm{nM}$ and $18 \mathrm{~b}$ showed high potency against HONE1 cell line with $\mathrm{IC}_{50} 666 \mathrm{nM}$. For the pyrimidine derivatives 19a-c, compound $19 \mathrm{c}$ with $\mathrm{X}=\mathrm{OCH}_{3}$ showed high potency against NUGC, DLDI, HA22, 
Table 1. Cytotoxicity of novel derivatives against a variety of cancer cell lines $\left[\mathrm{IC}_{50}{ }^{\mathrm{b}}\right.$ $(\mathrm{nM})]$.

\begin{tabular}{|c|c|c|c|c|c|c|c|}
\hline \multicolumn{5}{|c|}{ Compound } & \multicolumn{3}{|c|}{ Cytotoxocity (IC50 in nM) } \\
\hline & NUGC & DLDI & HA22T & HEPG2 & HONE1 & $\mathrm{MCF}$ & WI38 \\
\hline 3 & 1220 & 2068 & 1028 & 1432 & 2019 & 1880 & na \\
\hline 5 & 1329 & 3260 & 1120 & 1446 & 1240 & 1430 & na \\
\hline 7 & 3228 & 1248 & 2077 & 1686 & 3120 & 1133 & na \\
\hline 9 & 1487 & 3210 & 3240 & 2336 & 3382 & 2322 & 665 \\
\hline $11 \mathrm{a}$ & 2760 & 1185 & 2688 & 3311 & 2276 & 2355 & na \\
\hline $11 \mathrm{~b}$ & 49 & 36 & 66 & 320 & 39 & 286 & na \\
\hline $11 \mathrm{c}$ & 462 & 2102 & 1058 & 1260 & 1160 & 3320 & na \\
\hline 13 & 2366 & 1089 & 260 & 82 & 71 & 559 & na \\
\hline $15 a$ & 1180 & 1500 & 1981 & 1371 & 1289 & 1133 & na \\
\hline $15 b$ & 182 & 1062 & 560 & 299 & 3254 & 210 & na \\
\hline $15 c$ & 1280 & 2872 & 1329 & 1258 & 2107 & 1169 & na \\
\hline $17 \mathrm{a}$ & 270 & 348 & 163 & 331 & 178 & 2071 & na \\
\hline $17 \mathrm{~b}$ & 22 & 39 & 160 & 82 & 49 & 122 & na \\
\hline $17 \mathrm{c}$ & 39 & 682 & 211 & 202 & 130 & 52 & na \\
\hline $18 \mathrm{a}$ & 1750 & 368 & 1270 & 225 & 1140 & 310 & na \\
\hline $18 \mathrm{~b}$ & 2210 & 1011 & 1140 & 2134 & 666 & 1280 & na \\
\hline $18 \mathrm{c}$ & 2130 & 1148 & 2013 & 2176 & 1670 & 1742 & na \\
\hline $19 a$ & 2080 & 2188 & 3840 & 2060 & 3160 & 2246 & na \\
\hline $19 b$ & 1026 & 2180 & 2138 & 2132 & 2470 & 2140 & na \\
\hline $19 c$ & 880 & 488 & 150 & 1040 & 1188 & 504 & na \\
\hline 20 & 220 & 328 & 214 & 223 & 329 & 128 & na \\
\hline CHS 828 & 25 & 2315 & 2067 & 1245 & 15 & 18 & na \\
\hline
\end{tabular}

aNUGC, gastric cancer, DLDI, colon cancer, HA22T, liver cancer, HEPG2, liver cancer; HONEI, nasopharyngeal carcinoma; HR, gastric cancer; MCF, breast cancer; WI38, normal fibroblast cells.

and MCF cell lines. Finally, the thiazole derivative 20 showed high potency against the six cancer cell lines. Its high potency is attributed to the presence of high content of $\mathrm{N}$ and $\mathrm{S}$ together with the phenyl moiety through the molecule.

\section{Conclusions}

A series of new heterocyclic compounds with the thiazole nucleus were synthesized and characterized. Their cytotoxicity against six cancer cell lines was measured and the results showed that compounds $11 b, 11 c, 15 b, 17 a, 17 b, 17 c$, $19 \mathrm{c}$ and 20 were the most potent compounds among the synthesized compounds. The 2-amino-4-(4-chlorophenyl)-6-(4-phenylthiazol-2-yl)-4H-pyran-3, 5 -dicarbonitrile (17b) showed the maximum cytotoxicity among the synthesized compounds towards the six cancer cell lines.

\section{References}

[1] Bharti, S.K., Nath, G., Tilak, R. and Singh, S.K. (2010) Synthesis, Anti-Bacterial and Anti-Fungal Activities of Some Novel Schiff Bases Containing 2,4-Disubstituted Thiazole Ring. European Journal of Medicinal Chemistry, 45, 651-660. 
https://doi.org/10.1016/j.ejmech.2009.11.008

[2] Yang, B.V., Weinstein, D.S., Doweyko, L.M., Gong, H., Vaccaro, W., Huynh, T., Xiao, H.-Y., Doweyko, A.M., Mckay, L., Holloway, D.A., Somerville, J.E., Habte, S., Cunningham, M., McMahon, M., Townsend, R.,, Shuster, D., Dodd, J.H., Nadler, S.G. and Barrish, J.C. (2010) Dimethyl-Diphenyl-Propanamide Derivatives as Nonsteroidal Dissociated Glucocorticoid Receptor Agonists. Journal of Medicinal Chemistry, 53, 8241-8251. https://doi.org/10.1021/jm100957a

[3] Spector, F.C., Liang, L., Giordano, H., Sivaraja, M. and Peterson, M.G. (1998) Inhibition of Herpes Simplex Virus Replication by a 2-Amino Thiazole via Interactions with the Helicase Component of the UL5-UL8-UL52 Complex. Journal of Virology, 72, 6979-6987.

[4] Diego, G.C., Frederic, D., Feng, T.-S., Nchinda, A., Younis, Y., White, K.L., Wu, Q., Ryan, E., Burrows, J., Waterson, D., Witty, J.M., Wittlin, S., Charman, S.A. and Chibale, K. (2011) Novel Orally Active Antimalarial Thiazoles. Journal of Medicinal Chemistry, 54, 7713-7719. https://doi.org/10.1021/jm201108k

[5] Bell, F.W., Cantrell, A.S., Högberg, M., Jaskunas, S.R., Johansson, N.G., Jordan, C.L., Kinnick, M.D., Lind, P., Morin Jr, J.M., Noréen, R., Oberg, B., Palkoeitz, J.A., Parrish, C.A., Pranc, P., Sahiberg, C., Ternansky, R.J., Vasileff, R.T., Vrang, L., West, S.J., Zhang, H. and Zhou, X.-X. (1995) Phenethylthiazolethiourea (PETT) Compounds, a New Class of HIV-1 Reverse Transcriptase Inhibitors. 1. Synthesis and Basic Structure-Activity Relationship Studies of PETT Analogs. Journal of Medicinal Chemistry, 38, 4929-4936. https://doi.org/10.1021/jm00025a010

[6] Fink, B.E., Mortensen, D.S., Stauffer, S.R., Aron, Z.D. and Katzenellenbogen, J.A. (1999) Novel Structural Templates for Estrogen-Receptor Ligands and Prospects for Combinatorial Synthesis of Estrogens. Cell Chemical Biology, 6, 205-219. https://doi.org/10.1016/s1074-5521(99)80037-4

[7] Matteo, B., Colin, P.L., Angelica, M. and Caberlotto, L. (2010) Synthesis and Structure-Activity Relationship of N-(3-Azabicyclo[3.1.0]Hex-6-ylMethyl)-5-(2-Pyridinyl)-1,3-Tthiazol-2-Amines Derivatives as NPY Y5 Antagonists. Bioorganic and Medicinal Chemistry Letters, 20, 4741-4744.

https://doi.org/10.1016/j.bmcl.2010.06.140

[8] Tilburg, E.W.V., Van der Klein, P.A.M., Groote, M.D., Beukers, M.W. and Jzerman, A.P.I. (2001) Substituted 4-Phenyl-2-(Phenylcarboxamido)-1,3-Thiazole Derivatives as Antagonists for the AdenosineA1 Receptor. Bioorganic and Medicinal Chemistry Letters, 11, 2017-2019. https://doi.org/10.1016/S0960-894X(01)00356-0

[9] Bhoga, U. (2007) Novel Synthetic Approach to N-aryl-4-(3-Pyridyl)Thiazol-2Amine and Analogues Using HMCM-41 as Catalyst, and Their Biological Evaluation as Human Platelet Aggregation Inhibitors. European Journal of Medicinal Chemistry, 42, 1144-1150. https://doi.org/10.1016/j.ejmech.2007.01.016

[10] Wilson, K.J., Illig, C.R., Subasinghe, N. and Spurlino, J. (2001) Synthesis of Thiophene-2 -Carboxamidines Containing 2-Aminothiazoles and Their Biological Evaluation as Urokinase Inhibitors. Bioorganic and Medicinal Chemistry Letters, 11, 915-918. https://doi.org/10.1016/S0960-894X(01)00102-0

[11] Zhang, W.T., Ruan, J.L., Wu, P.F., Jiang, F.-C., Zhang, L.-N., Fang, W., Chen, X.-L., Wang, Y., Cao, B.-S., Chen, G.-Y., Zhu, Y.-J., Gu, J. and Chen, J.-G. (2009) Design, Synthesis, and Cytoprotective Effect of 2-Aminothiazole Analogues as Potent Poly (ADP-Ribose) Polymerase-1 Inhibitors. Journal of Medicinal Chemistry, 52, 718725. https://doi.org/10.1021/jm800902t

[12] Gebeyehu, G., Marquez, V.E., Cott, A.V., Cooney, D.A., Kelley, J.A., Jayaram, H.N., Ahluwalia, G.S., Dion, R.L., Wilson, Y.A. and Johns, D.G. (1985) Ribavirin, Tiazo- 
furin, and Selenazofurin: Mononucleotides and Nicotinamide Adenine Dinucleotide Analogues. Synthesis, Structure, and Interactions with IMP Dehydrogenase. Journal of Medicinal Chemistry, 28, 99-105. https://doi.org/10.1021/jm00379a018

[13] Sekhiguchi, A., Nishina, A., Kimura, H., Fukumoto, R.-H., Kanoh, K., Ishihara, H. and Koketsu, M. (2005) Superoxide Anion-Scavenging Effect of 2-Amino-1, 3-Selenazoles. Chemical and Pharmaceutical Bulletin, 53, 1439-1442. https://doi.org/10.1248/cpb.53.1439

[14] Koketsua, M., Ishihara, H., Wu, W., Murakami, K. and Saiki, I. (1999) 1,3-Selenazine Derivatives Induce Cytotoxicity and DNA Fragmentation in Human HT-1080 Fibrosarcoma Cells. European Journal of Pharmaceutical Sciences, 9, 157-161. https://doi.org/10.1016/S0928-0987(99)00058-5

[15] Hantzsch, A. and Weber, J.H. (1887) Ueber Verbindungen des Thiazols (Pyridins der Thiophenreihe). Berichte der deutschen chemischen Gesellschaft, 20, 31183132. https://doi.org/10.1002/cber.188702002200

Submit or recommend next manuscript to OALib Journal and we will provide best service for you:

- Publication frequency: Monthly

- 9 subject areas of science, technology and medicine

- Fair and rigorous peer-review system

- Fast publication process

- Article promotion in various social networking sites (LinkedIn, Facebook, Twitter, etc.)

- Maximum dissemination of your research work

Submit Your Paper Online: Click Here to Submit

Or Contact service@oalib.com 